Board of Governors of the Federal Reserve System

International Finance Discussion Papers

Number 1314

April 2021

\title{
From Micro to Macro: A Note on the Analysis of Aggregate Productivity Dynamics Using Firm-Level Data
}

Daniel A. Dias and Carlos Robalo Marques

Please cite this paper as:

Dias, Daniel A., and Carlos Robalo Marques (2021). "From Micro to Macro: A Note on the Analysis of Aggregate Productivity Dynamics Using Firm-Level Data," International Finance Discussion Papers 1314. Washington: Board of Governors of the Federal Reserve System, https://doi.org/10.17016/IFDP.2021.1314.

NOTE: International Finance Discussion Papers (IFDPs) are preliminary materials circulated to stimulate discussion and critical comment. The analysis and conclusions set forth are those of the authors and do not indicate concurrence by other members of the research staff or the Board of Governors. References in publications to the International Finance Discussion Papers Series (other than acknowledgement) should be cleared with the author(s) to protect the tentative character of these papers. Recent IFDPs are available on the Web at www.federalreserve.gov/pubs/ifdp/. This paper can be downloaded without charge from the Social Science Research Network electronic library at www.ssrn.com. 


\title{
From Micro to Macro: A Note on the Analysis of Aggregate Productivity Dynamics Using Firm-Level Data*
}

\author{
Daniel A. Dias ${ }^{\dagger}$ and Carlos Robalo Marques ${ }^{\ddagger}$
}

April 1, 2021

\begin{abstract}
In the empirical literature, the analysis of aggregate productivity dynamics using firm-level productivity has mostly been based on changes in the mean of logproductivity. This paper shows that there can be substantial quantitative and qualitative differences in the results relative to when the analysis is based on changes in the mean of productivity, and discusses the circumstances under which such differences are likely to happen. We use firm-level data for Portugal for the period 2006-2015 to illustrate the point. When the mean of productivity is used, we estimate that TFP and labor productivity for the whole economy increased by 17.7 percent and 5.2 percent, respectively, over this period. But, when the mean of log-productivity is used, we estimate that these two productivity measures declined by 4.3 percent and 1.8 percent, respectively. Similarly disparate results are obtained for productivity decompositions regarding the contributions for productivity growth of surviving, entering and exiting firms.
\end{abstract}

JEL classification: D24, E32, L25, O47

Key words: Jensen's inequality, productivity decomposition, geometric mean.

*The analyses, opinions and findings of this paper represent the views of the authors, which are not necessarily those of Banco de Portugal, the Eurosystem, the Board of Governors of the Federal Reserve System or of any other person associated with the Federal Reserve System.

${ }^{\dagger}$ Board of Governors of the Federal Reserve System and CEMAPRE. Email: daniel.dias@frb.gov

$\ddagger$ Banco de Portugal (Research Department). E-mail: cmrmarques@bportugal.pt 


\section{Introduction}

In this paper, we show that using the arithmetic mean of firm-level log-productivity or the arithmetic mean of firm-level productivity for analyzing aggregate productivity dynamics, based on firm-level data, can deliver substantially different results. These differences can occur not only in the estimation of average productivity growth, but also in the decomposition of productivity growth into the contributions of the different groups of firms operating in the economy (surviving, entering, and exiting firms).

The literature studying aggregate productivity dynamics using firm-level data usually defines firm-level productivity in logs (log-productivity) - e.g., log value added per worker and not value added per worker. One consequence of this choice is that the resulting aggregate measures of productivity are a weighted arithmetic mean of log-productivity or, equivalently, the logarithm of a weighted geometric mean of productivity (Baily et al. (1992), Griliches and Regev (1995), Foster et al. (2001), Olley and Pakes (1996), Foster et al. (2006), Hallward-Driemeier and Rijkers (2013), Dias et al. (2019)).

This issue may, at first sight, seem innocuous but it has some immediate implications for the interpretation of the results. For example, the geometric mean of value added per worker differs from the average value added per worker that is obtained from dividing value added in the economy by the number of workers. Thus, as Melitz and Polanec 2015) note, the arithmetic mean of firm-level log-productivity does not directly correspond to a measure that is relevant for aggregate welfare. In contrast, the arithmetic mean of firmlevel productivity, to the extent that it reproduces the aggregate economy's output per unit of input, lends itself to a direct relevant aggregate welfare interpretation. Moreover, and very importantly for the purpose of this paper, this equality in levels ensures the equality in changes, so that changes in the weighted arithmetic mean of firm-level productivity exactly coincide with changes in productivity measures that are obtained from the National Accounts aggregate data. 
Despite the potential advantage, the arithmetic mean has been overlooked in the literature, and most studies use the geometric mean ${ }^{1}$ We conjecture that the preference for using the geometric mean may be due to being easier to obtain or simply because researchers see the two measures as close substitutes that are expected to yield similar quantitative and qualitative results.

In this paper we show that using the arithmetic or the geometric mean of firm-level productivity to study aggregate productivity can deliver both quantitatively and qualitatively different results. Differences in the arithmetic and geometric means of firm-level productivity, stemming from Jensen's inequality, will most likely give rise to differences in the growth rates of the two statistics, through changes in the moments of the firm-level log-productivity distribution. We show that the importance and the direction of these differences depend on the correlations among productivity levels, productivity changes, size and size changes involving surviving, entering and exiting firms.

As an illustrative example, we use firm-level data for Portugal for the period 2006 to 2015 to compute two measures of aggregate productivity for the whole economy and for individual sectors of economic activity. We find that, in most cases, the arithmetic mean delivers very different results from the geometric mean, not only for aggregate productivity dynamics, but also for the contributions of the different types of firms operating in the economy (surviving, entering and exiting firms). In some cases the two measures even suggest opposite productivity developments. For instance, the arithmetic mean, for both total factor productivity (TFP) and labor productivity, suggests that productivity for the total economy increased between 2006 and 2015 (17.7 percent and 5.2 percent, respectively), but the geometric mean suggests otherwise, i.e., a decrease for the two pro-

\footnotetext{
${ }^{1}$ To the best of our knowledge, the single exception is the contribution by Melitz and Polanec (2015) who, besides the usual geometric mean, also conduct the analysis based on the arithmetic mean of productivity - this latter analysis is shown in the appendix and is not the main focus of the their paper. In their case, despite some sizable quantitative differences, the results based on the two alternative means deliver qualitatively similar results for aggregate productivity dynamics.
} 
ductivity measures (-4.3 percent and -1.8 percent, respectively). In the manufacturing sector, the contribution for total factor productivity growth of entering firms is positive according to the geometric mean, but negative according to the arithmetic mean, and similar opposite results are obtained for the contribution of exiting firms.

These findings cast serious doubts on the conclusions obtained in most empirical research that investigates aggregate productivity developments and productivity growth

decompositions based on changes in the mean of log-productivity (Baily et al. (1992), Griliches and Regev (1995), Olley and Pakes (1996), Foster et al. (2001), Foster et al. (2006), Decker et al. (2017), Decker et al. (2018), Dias et al. (2019)).

The rest of the paper is organized as follows: in section 2 we show analytically what may give rise to the different results based on the arithmetic and geometric means of firm-level productivity; in section 3 we use firm-level data from Portugal to illustrate the problem; and in section 4 we conclude.

\section{Theoretical background}

In this section we show that the arithmetic and geometric means of productivity deliver different results for aggregate productivity dynamics and provide the intuition for why this may happen.

\subsection{Jensen's inequality and measurement of aggregate produc- tivity dynamics}

Let X be a nonnegative random variable. Jensen's inequality tells us that

$$
E[X] \geqslant \exp (E[\ln [X]])
$$


that is, the mean of $\mathrm{X}$ is greater than or equal to the exponential of the mean of $\ln [X]$ (the equality holds if and only if $\mathrm{X}$ is degenerate or $E[\ln X]=\infty$ ). This condition may, similarly, be written as $\ln [E[X]] \geqslant E[\ln [X]]$, that is, the logarithm of the expected value of a random variable is greater than or equal to the expected value of its logarithm.2. $\mathrm{In}$ case $\mathrm{X}$ is a discrete random variable, $P\left[X=x_{i}\right]=q_{i} \geqslant 0, \mathrm{i}=1, \ldots, \mathrm{N}$, where $\sum q_{i}=1$ and $x_{i} \geqslant 0$, then inequality (1) may be written as

$$
\sum_{1}^{N} x_{i} q_{i} \geqslant \prod_{1}^{N} x_{i}^{q_{i}}
$$

that is, the (weighted) arithmetic mean is greater than or equal to the (weighted) geometric mean (the equality holds if and only if $x_{1}=\ldots=x_{n}$ or all but one $q_{i}=0$ ). Equations (1) and (2) are usually denoted in the literature as the arithmetic-geometric mean inequality (see Harry et al. (1952) and Marshall et al. (2010)).

If we assume that $\mathrm{X}$ is a random variable that represents firm-level productivity, an immediate implication of these results is that the arithmetic mean of firm-level productivity is greater than or equal to its geometric counterpart. However, while this result establishes a clear relationship between the arithmetic and geometric means of productivity it has not implications for productivity dynamics. For example, if both the arithmetic and geometric means of productivity grow at the same rate, the two measures will give equivalent results in terms of aggregate productivity dynamics, but there is no reason for that to happen. As such, an obvious question to be asked is what may makes the growth rates of the arithmetic and geometric means of productivity differ. To answer this question we first show how the arithmetic and geometric means are related with each other, and then discuss what can drive the difference in the growth rates of average productivity

\footnotetext{
${ }^{2}$ In the more general case, Jensen's inequality states that $g(E(X)) \geqq E[g(X)]$ for any concave function $\mathrm{g}($.$) . Here we stick to the special case of \mathrm{g}()=.\ln ($.$) , because we are concerned with the relationship$ between the arithmetic and geometric mean of $\mathrm{X}$.
} 
implied by the two measures.

To link the two means, that is $\exp (E[\ln [X]])$ and $E[X]$, we can use a Taylor series expansion of $\exp (x)$ around $E[\ln [X]]$. To start, let's write the Taylor series expansion of the exponential function $-\exp (x)-$ around a particular value of $x-x_{0}$ :

$$
\begin{aligned}
\exp (x) & =\exp \left(x_{0}\right)\left(1+\frac{\left(x-x_{0}\right)}{1}+\frac{\left(x-x_{0}\right)^{2}}{2}+\frac{\left(x-x_{0}\right)^{3}}{6}+\frac{\left(x-x_{0}\right)^{4}}{24}+\ldots\right) \\
& =\exp \left(x_{0}\right)\left(\sum_{i=0}^{\infty} \frac{\left(x-x_{0}\right)^{i}}{i !}\right)
\end{aligned}
$$

Based on this result, we can write productivity $X$ and its Taylor series expansion around $E(\ln [X])$, as follows:

$$
\begin{aligned}
X & =\exp (\ln [X])=\exp (E[\ln [X]])\left(\sum_{i=0}^{\infty} \frac{(\ln [X]-E[\ln [X]])^{i}}{i !}\right) \Rightarrow \\
E[X] & =\exp (E[\ln [X]]) E\left[\left(\sum_{i=0}^{\infty} \frac{(\ln [X]-E[\ln [X]])^{i}}{i !}\right)\right]
\end{aligned}
$$

Using the expression above, we can write how changes in $E[X]$ relate to changes in $E[\ln [X]]:$

$$
\frac{E\left[X_{t}\right]}{E\left[X_{t-1}\right]}=\frac{\exp \left(E\left[\ln \left[X_{t}\right]\right]\right)}{\exp \left(E\left[\ln \left[X_{t-1}\right]\right]\right)} \frac{E\left[\left(\sum_{i=0}^{\infty} \frac{\left(\ln \left[X_{t}\right]-E\left[\ln \left[X_{t}\right]\right]\right)^{i}}{i !}\right)\right]}{E\left[\left(\sum_{i=0}^{\infty} \frac{\left(\ln \left[X_{t-1}\right]-E\left[\ln \left[X_{t-1}\right]\right]\right)^{i}}{i !}\right)\right]}
$$

This expression tell us that, when moments of the distribution of log-productivity change, the change in the arithmetic mean of productivity is different from the change in the geometric mean. To give some intuition to this result, we consider a $3^{\text {rd }}$ order Taylor series expansion of productivity around its geometric mean. In this case, the formula 
above becomes:

$$
\frac{E\left[X_{t}\right]}{E\left[X_{t-1}\right]} \approx \frac{\exp \left(E\left[\ln \left[X_{t}\right]\right]\right)}{\exp \left(E\left[\ln \left[X_{t-1}\right]\right]\right)} \frac{\left(1+\operatorname{Var}\left[\ln \left[X_{t}\right]\right] / 2+\operatorname{Var}\left[\ln \left[X_{t}\right]\right]^{\frac{3}{2}} S K\left[\ln \left[X_{t}\right]\right] / 6\right)}{\left(1+\operatorname{Var}\left[\ln \left[X_{t-1}\right]\right] / 2+\operatorname{Var}\left[\ln \left[X_{t-1}\right]\right]^{\frac{3}{2}} S K\left[\ln \left[X_{t-1}\right]\right] / 6\right)}
$$

where Var and $S K$ stand for the variance and the Pearson's coefficient of skewness, respectively. From equation (4), we see that changes in the distribution of log-productivity that alter the dispersion (measured by the variance) and/or the symmetry (measured by the skewness) of the distribution of log-productivity will make the change in the arithmetic and geometric means of productivity different. When the variance and/or the skewness of log-productivity increase (decrease) the change in the geometric mean is going to underestimate (overestimate) the change in the arithmetic mean of productivity. When the variance and skewness of log-productivity move in opposite directions it is not possible to predict whether changes in the geometric mean of productivity overestimate or underestimate changes in the arithmetic mean of productivity. ${ }^{3}$

To get the intuition for why these differences may occur we now look at the empirical counterparts of the arithmetic and geometric means based on firm-level productivity, that are typically investigated in the context of aggregate productivity measures. For ease of presentation, we start with non-weighted means and a fixed number of firms (we assume that there is no entry and exit of firms, so that firms operating in the economy in periods t-1 and t are the same). In the next subsection we will tackle the general case of weighted means in the context of entry and exit of firms.

Under these simplifying assumptions the arithmetic mean is defined as the average of

\footnotetext{
${ }^{3}$ It is useful to note that the differences in average productivity growth implied by the differences in average productivity based on the arithmetic and the geometric means can be seen as a special case of the problems of using log-linearized models in econometrics. See Appendix A for the econometric details.
} 
firm-level productivity:

$$
P_{t}=\frac{1}{N} \sum_{i} P_{i t}
$$

where $P_{i t}$ stands for productivity of firm $i$ in period t, and the geometric mean may be written as:

$$
P_{t}^{*}=\left(\prod_{i} P_{i t}\right)^{\frac{1}{N}}
$$

so that its logarithm is given by:

$$
p_{t}=\frac{1}{N} \sum_{i} p_{i t}
$$

where $p_{i t}=\ln \left(P_{i t}\right)$ and $p_{t}=\ln \left(P_{t}^{*}\right)$.

Our variable of interest is the growth rate of productivity, so that we focus on $\beta_{t}=$ $\frac{P_{t}-P_{t-1}}{P_{t-1}}$ in equation 5 and $\beta_{t}^{*}=\Delta p_{t}=p_{t}-p_{t-1}$ in equation (6). We compute changes in the geometric mean using the log approximation, $\Delta p_{t}=p_{t}-p_{t-1}$, because this is the expression used in the empirical literature to study aggregate productivity decompositions based on firm-level data, and we are interested in studying the implications for productivity decompositions of such an approach.

From equations (5) and (6) we get:

$$
\beta_{t}-\beta_{t}^{*}=\sum_{i} \frac{1}{N} \frac{P_{i, t-1}}{P_{t-1}} \alpha_{i, t}-\sum_{i} \frac{1}{N} \Delta p_{i, t}=\frac{1}{N} \sum_{i}\left(\frac{P_{i, t-1}-P_{t-1}}{P_{t-1}}\right) \alpha_{i, t}+\frac{1}{N} \sum_{i}\left(\alpha_{i, t}-\Delta p_{i, t}\right)
$$

or simply:

$$
\beta_{t}-\beta_{t}^{*}=\operatorname{cov}\left(\eta_{i, t-1}, \alpha_{i, t}\right)+\left(\bar{\alpha}_{i, t}-\overline{\Delta p}_{i, t}\right)
$$


where $\alpha_{i, t}=\frac{P_{i, t}-P_{i, t-1}}{P_{i, t-1}}$ is the firm-level productivity change, and $\eta_{i, t-1}=\frac{P_{i, t-1}-P_{t-1}}{P_{t-1}}$, with $\sum_{i} \eta_{i, t-1}=0$, is the relative contribution of firm i to average productivity in $\mathrm{t}-1$.

Equation (7) shows that the difference between the rates of change of the two means may be written as the sum of two components: i) the covariance between the initial relative productivity levels $\left(\eta_{i, t-1}\right)$ and the firm-level productivity changes given by $\alpha_{i, t}$, and ii) the difference between the average of firm-level productivity changes $\left(\bar{\alpha}_{i, t}\right)$ and the average of the corresponding log approximations $\left(\overline{\Delta p}_{i, t}\right)$. We note that, given the properties of the log function, this second term is always positive $\left(\alpha_{i, t}>\Delta p_{i, t}\right)$, so that it contributes positively to the difference $\beta_{t}-\beta_{t}^{*}$. This contribution increases with the average of firm-level productivity changes 4 The first term, the covariance between the relative productivity levels and the firm-level productivity changes, may be positive or negative. If positive, it adds to the positive contribution of the second term and both contribute to a potentially large positive difference between the aggregate productivity changes delivered by the arithmetic and the geometric mean; if negative, it offsets the positive impact of the second term. Thus, whether the arithmetic and the geometric means deliver similar or very different growth rates for aggregate productivity is an empirical matter, and depends both on the average of firm-level productivity changes and the covariance between these firm-level productivity changes and productivity levels. In particular, the arithmetic mean will deliver higher aggregate productivity growth rates than the geometric mean $\left(\beta_{t}>\beta_{t}^{*}\right)$ if firm-level productivity changes are large and positively correlated with productivity levels (high productivity firms displaying higher productivity growth rates).

These results relate directly to equation (4). When productivity changes are correlated with productivity levels, changes in productivity alter the characteristics of the productivity distribution, namely its variance and possibly its skewness. In particular, if productivity changes are positively (negatively) correlated with productivity levels, changes

\footnotetext{
${ }^{4}$ Suppose, for instance, that the average of firm-level productivity changes is $10 \%\left(\bar{\alpha}_{i, t}=0.10\right)$. The contribution of the second component for the difference $\beta_{t}-\beta_{t}^{*}$, will be about 0.47 p.p., which is substantial.
} 
in productivity will increase (decrease) the variance and (possibly) the skewness of the productivity distribution.

\subsection{Implications of the arithmetic and geometric means for pro- ductivity decomposition}

In order to investigate the consequences for productivity decompositions, we now consider the general case of aggregate productivity, with time-varying weights and number of firms. In this context, we define the arithmetic mean as the weighted average of firm-level productivities:

$$
P_{t}=\sum_{i} \theta_{i t} P_{i t}
$$

where $P_{i t}$ stands for firm $i$ productivity and the shares $\theta_{i t} \geq 0$ sum to 1 . In turn, the weighted geometric mean is defined as:

$$
P_{t}^{*}=\prod_{i} P_{i t}^{\theta_{i t}}
$$

so that its logarithm is given by

$$
p_{t}=\sum_{i} \theta_{i t} p_{i t}
$$

where $p_{i t}=\ln \left(P_{i t}\right)$ and $p_{t}=\ln \left(P_{t}^{*}\right)$.

As before, our variable of interest is the growth rate of productivity, so that we focus

on $\frac{P_{t}-P_{t-1}}{P_{t-1}}$ in equation (8) and on $\Delta p_{t}=p_{t}-p_{t-1}$ in equation (9). As a way of introducing the discussion on productivity decompositions, we start by focusing on equation (9), as this is the measure of aggregate productivity investigated in the literature.

Following Dias and Marques (2019), we use a decomposition of aggregate productivity 
growth, which results from a combination of the Melitz and Polanec (2015) and the Foster et al. (2001) decompositions. Let firms at time $t$ be categorized as survivors $\left(S_{t}\right)$, entrants $\left(E_{t}\right)$ and exiters $\left(X_{t}\right)$, and define $\theta_{k t}=\sum_{i \in k} \theta_{i t}$ as the aggregate market share of category $\mathrm{K}$ of firms $\left(\mathrm{K}=S_{t}, E_{t}, X_{t}\right) !^{5}$ In the context of the geometric mean, we define the average aggregate productivity of group $\mathrm{K}$ of firms as $p_{k t}=\sum_{i \in k}\left(\theta_{i t} / \theta_{k t}\right) p_{i t}=\sum_{i \in k} \mu_{i t}^{k} p_{i t}$, where $\mu_{i t}^{k}=\theta_{i t} / \theta_{k t}$, with $\sum_{i \in k} \mu_{i t}^{k}=1$, for $\mathrm{K}=S_{t}, E_{t}, X_{t}$. Melitz and Polanec (2015) show that we can express aggregate productivity, given by equation (9), for periods t and t-1, as a function of the aggregate share and aggregate productivity of surviving, entering and exiting firms, where $\theta_{i, t-1}=0$ for entrants and $\theta_{i, t}=0$ for exiters:

$$
\begin{aligned}
p_{t-1} & =\theta_{s, t-1} p_{s, t-1}+\theta_{x, t-1} p_{x, t-1}=p_{s, t-1}+\theta_{x, t-1}\left(p_{x, t-1}-p_{s, t-1}\right) \\
p_{t} & =\theta_{s, t} p_{s, t}+\theta_{e, t} p_{e, t}=p_{s, t}+\theta_{e, t}\left(p_{e, t}-p_{s, t}\right)
\end{aligned}
$$

From these equations we can compute the aggregate productivity change $\Delta p_{t}=p_{t}-$ $p_{t-1}$ in terms of the contribution of each group of firms:

$$
\Delta p_{t}=\left(p_{s, t}-p_{s, t-1}\right)+\theta_{e, t}\left(p_{e, t}-p_{s, t}\right)+\theta_{x, t-1}\left(p_{s, t-1}-p_{x, t-1}\right)
$$

The contribution of surviving firms, $p_{s, t}-p_{s, t-1}$, can be decomposed further, and there are several possibilities. For example, Melitz and Polanec (2015) suggest decomposing the contribution of these firms using the Olley-Pakes decomposition (Olley and Pakes (1996)). Alternatively, we can follow an approach similar to that of Baily et al. (1992), Griliches \begin{tabular}{l}
${ }^{5}$ In each year, the firms operating in the economy may be classified into three types: firms that began \\
the activity in that year (entrants or entering firms), firms that ceased activity in that year (exiters or \\
exiting firms) and firms, which are active and survive to the next year (incumbents, survivors or surviving \\
\hline firms).
\end{tabular} 
and Regev (1995), and Foster et al. (2001) and re-write equation (10) as:

$$
\Delta p_{t}=\sum_{i \in S} \mu_{i, t-1}^{s} \Delta p_{i, t}+\sum_{i \in S} p_{i, t-1} \Delta \mu_{i, t}^{s}+\sum_{i \in S} \Delta \mu_{i, t}^{s} \Delta p_{i, t}+\theta_{e, t}\left(p_{e, t}-p_{s, t}\right)+\theta_{x, t-1}\left(p_{s, t-1}-p_{x, t-1}\right)
$$

The first term in this decomposition represents the so-called "within" effect, i.e., the contribution to productivity growth of within-firm productivity changes of surviving firms, weighted by initial market shares, $\mu_{i, t-1}^{s}$. The second term represents the "between" effect, i.e., the contribution of market share reallocation to productivity growth, weighted by the initial productivity level, $p_{i, t-1}$. The third term represents the "cross" effect (covariance type effect) and measures the extent to which firm-level productivity changes $\left(\Delta p_{i, t}\right)$ are associated with changes in size $\left(\Delta \mu_{i, t}^{s}\right)$. Finally, the fourth and fifth terms represent the contribution of entering ("entry" effect) and exiting firms ("exit" effect) for productivity growth, respectively.

Similarly, the change of the arithmetic mean, as given by equation (8), may be written as:

$$
\frac{P_{t}-P_{t-1}}{P_{t-1}}=\frac{P_{s, t}-P_{s, t-1}}{P_{t-1}}+\theta_{e, t} \frac{\left(P_{e, t}-P_{s, t}\right)}{P_{t-1}}+\theta_{x, t-1} \frac{\left(P_{s, t-1}-P_{x, t-1}\right)}{P_{t-1}}
$$

where the terms on the right hand side capture the contribution for productivity growth of surviving, entering and exiting firms, respectively. $]^{7}$

${ }^{6}$ Note that for surviving firms we have:

$$
p_{s, t}-p_{s, t-1}=\sum_{i \in S} \mu_{i, t}^{s} p_{i, t}-\sum_{i \in S} \mu_{i, t-1}^{s} p_{i, t-1}=\sum_{i \in S} \mu_{i, t-1}^{s} \Delta p_{i, t}+\sum_{i \in S} p_{i, t-1} \Delta \mu_{i, t}^{s}+\sum_{i \in S} \Delta \mu_{i, t}^{s} \Delta p_{i, t}
$$

${ }^{7}$ To our knowledge, this decomposition has never been used in the literature. The only contribution addressing the decomposition of an arithmetic mean, that we are aware of, is the one by Melitz and Polanec (2015), but the authors look at $\left(P_{t}-P_{t-1}\right) / \bar{P}_{t}$ where $\bar{P}_{t}=\left(P_{t}+P_{t-1}\right) / 2$. The use of $\bar{P}_{t}$ in the denominator, instead of $P_{t-1}$, changes the interpretation of the different components, as part of the "within", "between", "cross" and "entry" effects is introduced in the denominator through $P_{t}$. Thus, we 
Similarly to (11), equation $(12)$ may be decomposed further in order to distinguish the "between", "within" and "cross" effects of surviving firms:

$$
\begin{aligned}
\frac{P_{t}-P_{t-1}}{P_{t-1}} & =\sum_{i \in S} \mu_{i, t-1}^{s} \frac{P_{i, t-1}}{P_{t-1}} \alpha_{i, t}+\sum_{i \in S} \frac{P_{i, t-1}}{P_{t-1}} \Delta \mu_{i, t}^{s}+\sum_{i \in S} \frac{P_{i, t-1}}{P_{t-1}} \Delta \mu_{i, t}^{s} \alpha_{i, t} \\
& +\theta_{e, t} \frac{\left(P_{e, t}-P_{s, t}\right)}{P_{t-1}}+\theta_{x, t-1} \frac{\left(P_{s, t-1}-P_{x, t-1}\right)}{P_{t-1}}
\end{aligned}
$$

where, again, $\alpha_{i, t}=\frac{P_{i, t}-P_{i, t-1}}{P_{i, t-1}}$. Now, denoting $\frac{P_{t}-P_{t-1}}{P_{t-1}}=\beta_{t}$ and $\Delta p_{t}=\beta_{t}^{*}$, the overall difference between changes in the arithmetic and the geometric means may be written as:

$$
\begin{aligned}
\beta_{t}-\beta_{t}^{*} & =\sum_{i \in S} \eta_{i, t-1} \mu_{i, t-1}^{s} \alpha_{i, t}+\sum_{i \in S} \mu_{i, t-1}^{s}\left(\alpha_{i, t}-\Delta p_{i, t}\right) \\
& +\sum_{i \in S} \lambda_{i, t-1} \Delta \mu_{i, t}^{s} \\
& +\sum_{i \in S} \eta_{i, t-1} \Delta \mu_{i, t}^{s} \alpha_{i, t}+\sum_{i \in S} \Delta \mu_{i, t}^{s}\left(\alpha_{i, t}-\Delta p_{i, t}\right) \\
& +\theta_{e, t}\left[\sum_{i \in E} \mu_{i, t}^{e} \lambda_{i, t}-\sum_{i \in S} \mu_{i, t}^{s} \lambda_{i, t}\right] \\
& +\theta_{x, t-1}\left[\sum_{i \in S} \mu_{i, t-1}^{s} \lambda_{i, t-1}-\sum_{i \in X} \mu_{i, t-1}^{x} \lambda_{i, t-1}\right]
\end{aligned}
$$

where $\eta_{i, t-1}=\left(\frac{P_{i, t-1}-P_{t-1}}{P_{t-1}}\right), \lambda_{i, t}=\left(\frac{P_{i, t}}{P_{t-1}}-\ln \left(\frac{P_{i, t}}{P_{t-1}}\right)\right)$ and $\lambda_{i, t-1}=\left(\frac{P_{i, t-1}}{P_{t-1}}-\ln \left(\frac{P_{i, t-1}}{P_{t-1}}\right)\right) \cdot 8$

We can now use equation (14) to discuss the conditions under which the two means are expected to deliver different numbers for each of the individual contributions and thus also for aggregate productivity growth. In order to facilitate the discussion that follows, we note that the difference for each individual contribution ("within", "between", "cross", "entry" and "exit" effects) is recorded in a different row of equation (14).

stick to our definition $\sqrt{12}$ as a way of making the results as much comparable as possible to the ones of equation 11 .

${ }^{8}$ The derivation of equation 14 uses the fact that $\sum_{i \in S} \ln \left(P_{t-1}\right) \Delta \mu_{i, t}^{s}=0$ and $\sum_{i \in S} \mu_{i, t}^{s} \ln \left(P_{t-1}\right)=$ $\sum_{i \in E} \mu_{i, t}^{e} \ln \left(P_{t-1}\right)=\sum_{i \in X} \mu_{i, t}^{x} \ln \left(P_{t-1}\right)=\ln \left(P_{t-1}\right)$. 


\subsubsection{Differences in the contribution of surviving firms}

We start the discussion by looking at the differences in the contributions of surviving firms, regarding the "within", "between" and "cross" effects. The difference between the contributions of the "within" effect (first row in equation (14)) depends on the sum of two components, which are similar to the ones presented above in equation (7) for the simplest case: i) the correlation between the weights $\left(\eta_{i, t-1} \mu_{i, t-1}^{s}\right)$ and firm-level productivity changes $\alpha_{i, t}$, and ii) the weighted average of the difference between firm-level productivity changes, measured by $\alpha_{i, t}$, and their log approximations, $\Delta p_{i, t}$. The second component is always positive, so that it contributes to a higher "within" effect of the arithmetic mean ${ }^{9}$ The first component can be positive or negative. For instance, it will be positive if, on average, (size-adjusted) high productivity firms (firms for which $\eta_{i, t-1} \mu_{i, t-1}^{s}$ is above the mean) display higher productivity changes. Thus, as a general rule, one may expect the contribution of the "within" effect to be larger under the arithmetic mean than the geometric mean. The exception occurs only if productivity changes are negatively correlated with productivity levels and this correlation is strong enough to offset the positive contribution of the second component.

We note that negative or positive correlations between productivity changes and productivity levels may be related to interesting economic situations. A positive correlation is expected to emerge in the presence of large "superstar" firms, i.e., when an important fraction of high productivity firms also displays higher productivity growth. This will increase the dispersion of the productivity distribution. In contrast, a negative correlation is expected to emerge in the presence of a catching-up process, through which low productivity firms (usually young firms) display higher productivity growth than high productivity

\footnotetext{
${ }^{9}$ This positive contribution will tend to be larger in the presence of a positive correlation between the weights, $\mu_{i, t-1}$, and the gaps, $\alpha_{i, t}-\Delta p_{i, t}$, (larger firms displaying larger productivity changes, on average). This component also increases with firm-level productivity changes: the difference, $\alpha_{i, t}-\Delta p_{i, t}$, which is always positive, increases with $\alpha_{i, t}$.
} 
firms, leading to a concentration of the productivity distribution. In the presence of these dynamic processes, the arithmetic and geometric means of productivity can deliver very different results about the "within" effect.

Regarding the "between" effect (second row in the decomposition), we note that $\lambda_{i, t-1}$ is a positive $\mathrm{U}$-shaped convex function that reaches its minimum at $\frac{P_{i, t-1}}{P_{t-1}}=1$, i.e., for a firm whose productivity, $P_{i, t-1}$ equals the initial mean, $P_{t-1}$. This function increases not only when $P_{i, t-1}$ decreases (if $P_{i, t-1}<P_{t-1}$ ), but also when $P_{i, t}$ increases (if $P_{i, t-1}>P_{t-1}$ ). Overall, given that $\sum_{i \in S} \Delta \mu_{i t}^{s}=0$, the difference between the "between" effect as delivered by the two means will be positive (negative) if the covariance between $\lambda_{i, t-1}$ and $\Delta \mu_{i t}^{s}$ is positive (negative). Given that $\lambda_{i, t-1}$ is large for both high and low productivity firms, a positive (negative) covariance will emerge if increases (decreases) in size tend to be associated with firms in the tails of the productivity distribution, prevailing in period t-1.

Regarding the "cross" term, the difference between the two means (third row of equation (14)) stems from the fact that $\alpha_{i, t}>\Delta p_{i, t}$ and, in general, $\eta_{i, t-1} \neq 0$. Whether this difference is large (positive or negative) depends on the sign and magnitude of the correlation involving $\eta_{i, t-1}$ and $\Delta \mu_{i, t}^{s} \alpha_{i, t}$ on the one side, and the covariance between $\Delta \mu_{i, t}^{s}$ and $\left(\alpha_{i, t}-\Delta p_{i, t}\right)$, on the other.

Some authors do not separate the "between" and "cross" effects (see, for instance, Baily et al. (1992)). The sum of these two terms has an interesting interpretation on its own: it measures the contribution for aggregate productivity growth of resource reallocation involving surviving firms. If we aggregate these two terms, we get $\sum_{i \in S} \lambda_{i, t} \Delta \mu_{i, t}^{s}$ for the difference between the two means, which is just the covariance between $\lambda_{i, t}$ and $\Delta \mu_{i, t}^{s}$. In particular, the difference between the "between" plus "cross" effects in the two means will be positive if increases in size, $\left(\Delta \mu_{i, t}^{s}>0\right)$, tend to be associated with very high or very low productivity firms, i.e., firms in the tails of the productivity distribution, prevailing in period $t$. 
In summary, the differences between changes in the two means regarding surviving firms stem from two sources: i) the difference between firm-level productivity changes, measured by $\alpha_{i, t}$, and their log approximations, $\Delta p_{i, t}$ (which is always positive) and ii) the correlations involving productivity changes, firm's size changes and productivity levels. In particular, changes in aggregate productivity generated by the arithmetic mean will be bigger than changes generated by the geometric mean if firm-level productivity changes and firm's size changes are positively correlated with firm-level productivity.

\subsubsection{Differences in the contributions of entering and exiting firms}

We now look at the contributions of entering and exiting firms. From equation (14), we conclude that the difference between the contributions of the arithmetic and geometric means for the "entry" effect is positive if $\sum_{i \in E} \mu_{i, t}^{e} \lambda_{i, t}>\sum_{i \in S} \mu_{i, t}^{s} \lambda_{i, t}$. It is easy to show that $\sum_{i \in E} \mu_{i, t}^{e} \lambda_{i, t}=N_{e, t} \cdot \operatorname{cov}\left(\mu_{i, t}^{e}, \lambda_{i, t}\right)+\bar{\lambda}_{e, t}$ where $N_{e, t}$ is the number of entering firms and $\bar{\lambda}_{e, t}$ is the mean of $\lambda_{i, t}$ for entering firms. Using a similar expression for surviving firms, we conclude that the condition above holds if $\operatorname{cov}\left(\mu_{i, t}^{e}, \lambda_{i, t}\right)>\frac{N_{s, t}}{N_{e, t}} \cdot \operatorname{cov}\left(\mu_{i, t}^{s}, \lambda_{i, t}\right)+\frac{1}{N_{e, t}}\left(\bar{\lambda}_{s, t}-\bar{\lambda}_{e, t}\right)$. Thus, the larger $\operatorname{cov}\left(\mu_{i, t}^{e}, \lambda_{i, t}\right)$ and $\bar{\lambda}_{e, t}$, the higher the probability for the contribution of entering firms generated by the arithmetic mean to be larger than the contribution generated by the geometric mean, 10

In turn, the difference between the contributions of the arithmetic and geometric means for the "exit" effect is positive if $\sum_{i \in X} \mu_{i, t-1}^{x} \lambda_{i, t-1}<\sum_{i \in S} \mu_{i, t-1}^{s} \lambda_{i, t-1}$. Similarly to the "entry" effect, this condition for "exit" may be written as $\operatorname{cov}\left(\mu_{i, t-1}^{x}, \lambda_{i, t-1}\right)<$ $\frac{N_{s, t-1}}{N_{x, t-1}} \cdot \operatorname{cov}\left(\mu_{i, t-1}^{s}, \lambda_{i, t-1}\right)+\frac{1}{N_{x, t-1}}\left(\bar{\lambda}_{s, t-1}-\bar{\lambda}_{x, t-1}\right)$, so that the smaller $\operatorname{cov}\left(\mu_{i, t-1}^{x}, \lambda_{i, t-1}\right)$ and $\bar{\lambda}_{x, t-1}$, the larger the probability for the for the contribution of exiting firms generated by the arithmetic mean to be larger than the contribution generated by the geometric mean.

\footnotetext{
${ }^{10}$ Because $\lambda_{i, t}$ is a positive U-shaped convex function, a large positive covariance between size, $\mu_{i, t}$, and $\lambda_{i, t}$ will be obtained if size and productivity are either positively or negatively correlated. In turn, a large $\bar{\lambda}_{e, t}$ will be obtained if productivity of entering firms is largely above or largely below $P_{t-1}$, the initial average aggregate productivity.
} 
In summary, the differences between the arithmetic and geometric means regarding the contributions for productivity growth of entering and exiting firms depend on the strength of the correlations between size and productivity of entering and exiting firms, on the one side, and surviving firms, on the other.

\section{$3 \quad$ Empirical evidence}

To show how the arithmetic and geometric means can yield very different results in the analysis of aggregate productivity dynamics, we compute two measures of productivity commonly used in the literature: a labor productivity measure defined on value added, and a total factor productivity measure (TFP) defined on gross output. More specifically, the labor productivity measure is defined as the ratio of real value added to employment (number of employees) at the firm-level, while TFP is computed from a three input CobbDouglas production function defined on real gross output 11

To get sector-level or economy-wide average productivity measures, we need to choose the weights, $\theta_{i t}$, to be used in equations (8) and (9). When aggregating labor productivity measures, employment or hours worked emerge as natural choices as they allow reproducing exactly average productivity that we get from aggregate sector data, i.e., dividing sector-level output by sector-level employment (or total hours worked) ${ }^{12}$ When aggregating firm-level TFP two distinct types of weights have been used by the literature: the gross-output or value-added shares (Baily et al. (1992), Foster et al. (2001), Olley and Pakes (1996), Griffin and Odaki (2009), Hallward-Driemeier and Rijkers (2013), Melitz and Polanec (2015)) and the composite-input shares (Liu and Tybout (1996) and Bar-

\begin{tabular}{l}
\hline \hline${ }^{11}$ The production functions are estimated at the industry level using the Levinsohn-Petrin estimator \\
(see Levinsohn and Petrin (2003)), to account for the endogeneity of the regressors. \\
\hline \hline${ }^{12}$ Nevertheless, gross output and gross value added have also been used as weights to obtain aggregate \\
measures of labor productivity (see Foster et al.| (2001), Griffin and Odaki (2009), Hallward-Driemeier \\
and Rijkers (2013)).
\end{tabular}


telsman and Dhrymes (1998)). In this paper, firm-level productivities are aggregated at the sectoral or total economy level using, as weights, the shares of employment for labor productivity and the log of the composite input for TFP ${ }^{13}$

\subsection{The data}

To compute firm-level productivity measures, we use data that draw on annual information for Portuguese firms reported under the Informação Empresarial Simplificada (IES), covering the period 2006 to 2015. The IES dataset has data since 2006 and covers virtually the universe of Portuguese non-financial firms. The data provide very detailed information on the firms' balance sheets and income statements. From this dataset, we get information on firm's gross output, value added, consumption of intermediate inputs, labor costs, employment, gross fixed capital formation, capital depreciations, and the book values of the capital stock.

Before using the data, we clean the dataset by dropping firms that do not report strictly positive figures for gross output (production), labor costs, employment, capital stock, intermediate consumption and value added. After cleaning the data, we are left with a number of firms that varies between 240,030 in 2006 and 247,575 in 2015 .

Table 1 records the relative importance of the main sectors of activity in our dataset (agriculture, manufacturing, construction, utilities and services) in terms of gross output (GO), gross value added (GVA) and employment (Emp). Note the small contribution of agriculture for total employment and value added (around 2 percent), while manufacturing contributes around 25 percent and the service sector around 60 percent ${ }^{14}$ Table 1 also

\footnotetext{
${ }^{13}$ The composite input is defined as a geometric mean of inputs using estimated factor elasticities. The use of the log transformation is used as an alternative to trimming and winsorizing do deal with outliers in the composite input. See Dias et al. (2019), Appendix B, for a discussion.

${ }^{14}$ According to information from the National Accounts, in 2010, agriculture, manufacturing, construction, utilities and services contribute 2.3, 13.8, 6.2, 3.9 and 73.8 percent for aggregate GDP, respectively. Thus, if anything, our dataset appears to be slightly skewed towards manufacturing and against the service sector. We note, however, that in contrast to the National Accounts, services in our dataset do not
} 
distinguishes between tradable and nontradable services.15 Tradable services contribute about 12 percent to total value added and correspond to about 20 percent of the service sector.

Table 1: Relative importance of each sector in the dataset

(Percentage)

\begin{tabular}{|l|r|r|r|r|r|r|r|r|r|}
\hline \hline & \multicolumn{3}{|c|}{2006} & \multicolumn{3}{c|}{2010} & \multicolumn{3}{c|}{2015} \\
\hline \hline & GO & GVA & Emp. & GO & GVA & Emp. & GO & GVA & Emp. \\
\hline Agric. & 2.0 & 2.1 & 2.1 & 2.1 & 1.9 & 2.2 & 2.5 & 2.2 & 2.6 \\
Manuf. & 32.9 & 25.6 & 27.9 & 31.5 & 23.1 & 24.0 & 34.8 & 25.1 & 24.4 \\
Const. & 15.0 & 11.5 & 13.2 & 13.9 & 10.3 & 12.4 & 7.6 & 7.0 & 8.7 \\
Utilities & 3.3 & 4.4 & 0.4 & 2.7 & 4.0 & 0.4 & 6.4 & 4.4 & 0.5 \\
Services & 46.8 & 56.4 & 56.3 & 49.9 & 60.6 & 61.0 & 48.6 & 61.4 & 63.8 \\
\hline T. serv. & 10.3 & 10.3 & 8.8 & 11.8 & 12.1 & 9.9 & 12.4 & 13.4 & 10.7 \\
NT. serv. & 36.6 & 46.2 & 47.5 & 38.1 & 48.5 & 51.2 & 36.3 & 48.0 & 53.1 \\
\hline \hline
\end{tabular}

Note: agriculture also includes forestry, fishing, mining and quarrying; the utilities sector includes electricity, gas and water services.

To obtain estimates for real gross output, real value added and real intermediate consumption, we use industry-level price indices. The price indices for the manufacturing sector were built with information from the disaggregated manufacturing production price index, obtained from the Instituto Nacional de Estatistica (Statistics Portugal). For the non-manufacturing industries, for which no price index was available, we used alternative deflators depending on the type of industry (disaggregated items of the consumer price index and the investment goods deflator). In order to compute the real stock of capital, we used the perpetual inventory method, with a special adjustment factor for the first year of the sample (2006). This approach is similar to that used by Foster et al. (2016) and the details of the procedure can be found in Dias and Marques (2019).

include information of the government sector, the financial sector and self-employment.

${ }^{15}$ The distinction among tradable and nontradable industries follows Amador and Soares (2012). They define as tradable the industries for which the export to sales ratio is above 15 percent, along with all the manufacturing industries. 
The dataset also includes information on the firm's main industry of operation based on NACE classification (Rev. 2.1 and Rev. 3) both at 3- and 5-digit disaggregation level. However, the exercises in our paper are conducted with industries defined at the 3-digit NACE code (Rev. 2.1) because we do not have information on prices at a higher disaggregation level, and also because the number of firms at a 5-digit classification will be very small for many industries, making it impossible to estimate the corresponding production functions. After dropping industries with less than 10 firms (to avoid estimation problems), we are left with 202 industries defined at the 3-digit NACE code classification - 16 for agriculture (including forestry, fishing, mining and quarrying), 101 for manufacturing and 85 for services (including construction and utilities).

\subsection{Productivity changes based on the arithmetic and geometric means}

Figures 1, 2 and 3 compare the arithmetic and geometric means for the two productivity measures - labor productivity and TFP - for the total economy and some sectors of activity (agriculture, manufacturing, tradable and nontradable services). In turn, Table 2 records the productivity growth rates of these two productivity measures for the full sample period (2006-2015).

Our results show that, for most cases, the arithmetic and geometric means deliver substantially different results about aggregate productivity dynamics in Portugal. The only exception is labor productivity for agriculture, where the two means suggest a similar growth rate for the full period and not very different dynamics (Figure 2). In all other cases, the arithmetic and the geometric means deliver very different productivity growth rates for the full sample period, as well as very different time profiles for productivity dynamics. With the exception of agriculture, the geometric mean delivers much lower productivity growth rates than the arithmetic mean. 
Table 2: Productivity growth (2006-2015):

(Arithmetic vs. geometric mean (Percentage))

\begin{tabular}{l|c|c|c|c|c}
\hline \hline & Agriculture & Manufacturing & $\begin{array}{c}\text { Tradable } \\
\text { Services }\end{array}$ & $\begin{array}{c}\text { Nontradable } \\
\text { Services }\end{array}$ & $\begin{array}{c}\text { Total } \\
\text { Economy }\end{array}$ \\
\hline \hline Labor productivity: & & & & & \\
Arithmetic & -11.9 & 20.2 & -11.7 & 4.0 & 5.4 \\
Geometric & -12.4 & 16.5 & -29.7 & -3.0 & -1.8 \\
\hline TFP: & & & & & \\
Arithmetic & 4.5 & 16.7 & 28.6 & 8.9 & 18.0 \\
Geometric & 9.5 & 7.1 & 8.9 & -5.3 & -4.3 \\
\hline \hline
\end{tabular}

Note: agriculture also includes forestry, fishing, mining and quarrying; total economy also includes construction, but excludes the utilities sector (electricity, gas and water services).

In some cases the two measures even suggest opposite productivity developments. According to Figure 1 and Table 2 the arithmetic mean for both labor productivity and TFP, suggests that productivity increased over time for the total economy (5.4 percent and 18.8 percent, respectively), but the geometric mean suggests otherwise, i.e., a decrease for the two productivity measures (-1.8 percent and -4.3 percent, respectively). These accumulated changes imply large differences in the average annual growth rates between the arithmetic and the geometric means: 1.9 percent against -0.5 percent in case of TFP, and 0.6 percent against -0.2 percent in case of labor productivity. Large quantitative differences are also detected for some of the activity sectors, such as tradable and nontradable services.

Overall, the evidence in this section shows that the geometric and the arithmetic means, in the case of Portuguese data, give rise to very different messages regarding aggregate and sector level productivity developments.

In section 2 we showed that the difference between the estimates of aggregate productivity growth based on the arithmetic and the geometric means of firm-level productivity are the result of systematic changes in the distribution of firm-level productivity. To see how much of the differences in the results based on the two means can be explained by changes in the variance and skewness of the distribution of firm-level log-productivity, we 
Labor productivity

(Total economy)

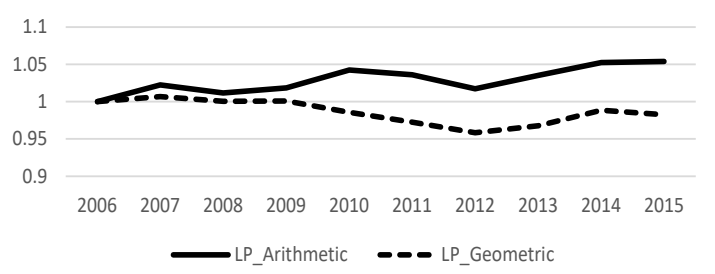

TFP

Total economy

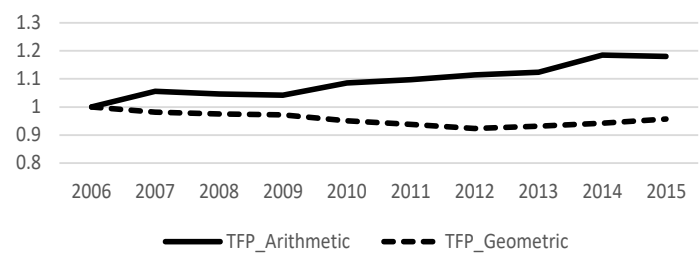

Figure 1: Labor productivity and TFP: Arithmetic vs. geometric means
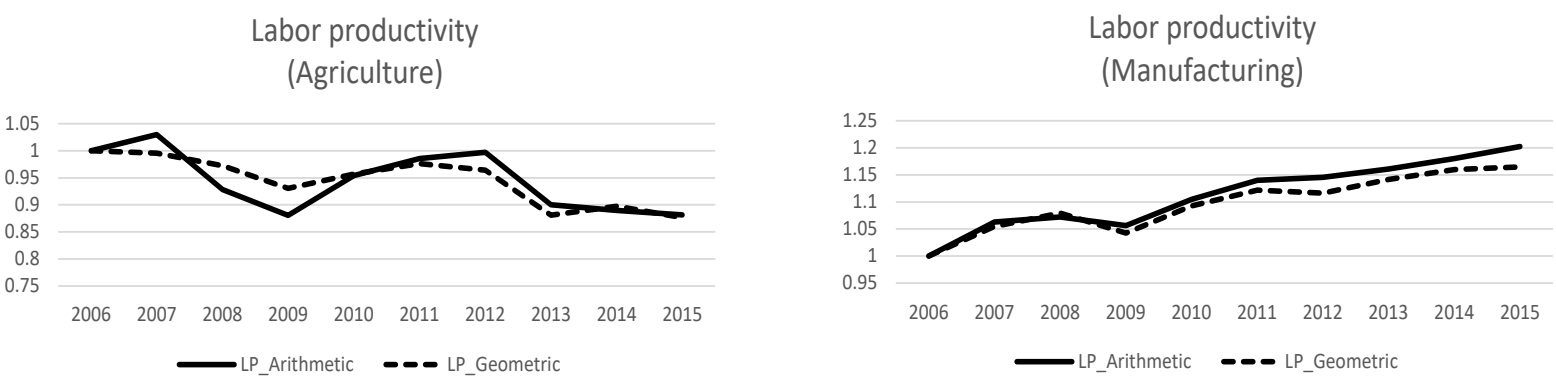

Labor productivity

(Tradable services)

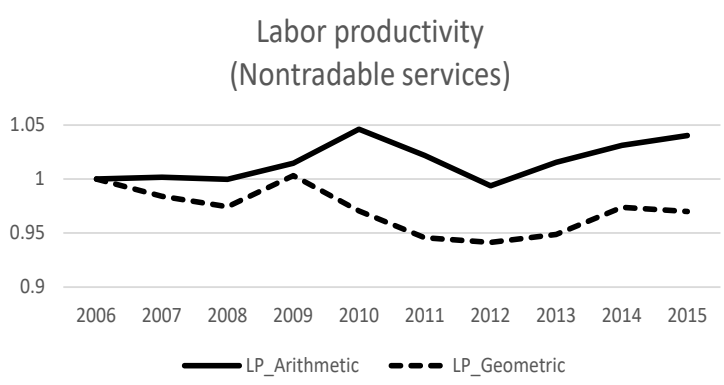

Figure 2: Labor productivity: Arithmetic vs. geometric mean 
TFP

(Agriculture)

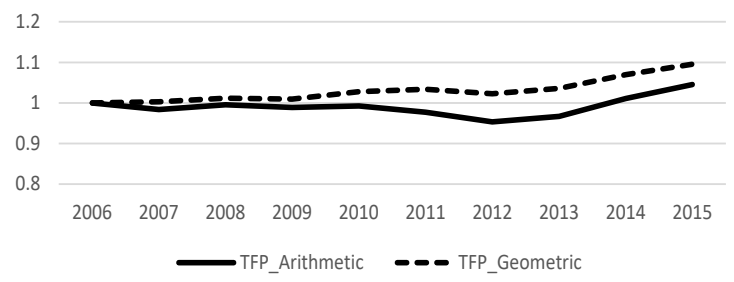

TFP

(Tradable services)

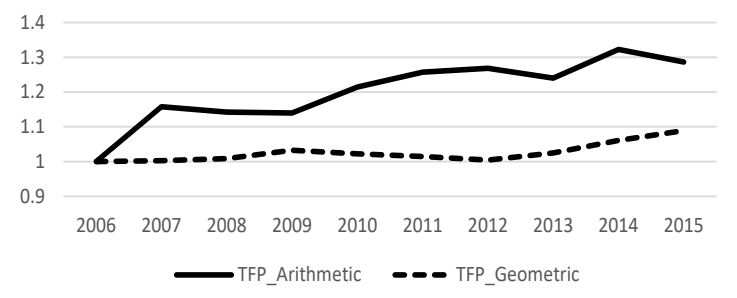

TFP

(Manufacturing)

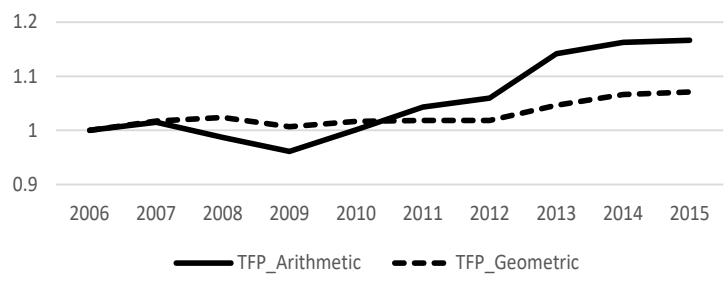

TFP

(Nontradable services)

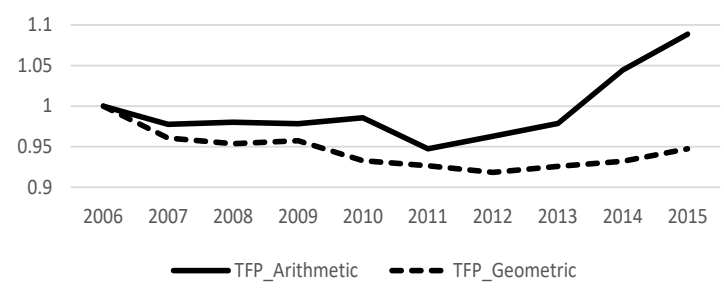

Figure 3: TFP: Arithmetic vs. geometric mean

calculate these two statistics at the beginning (2006) and at the end (2015) of the sample period, and use these numbers to calculate the second term on the right-hand-side of equation (4). By dividing the second term on the right-hand-side of this equation by the total difference in the growth rate, we get an estimate of how much of the difference between the results based on the arithmetic and geometric means can be explained by changes in the variance and skewness of the distribution of firm-level log-productivity. The results of this exercise are shown in Table 3. The values in columns (5) and (6) can be interpreted as the share of the difference between the arithmetic and the geometric means that can be attributed to changes in the variance or in the variance and skewness of the firm-level log-productivity distribution, respectively. ${ }^{16}$

\footnotetext{
${ }^{16}$ Column (2) of Table 3 is obtained from equation (4) and corresponds to the ratio $\frac{E\left[X_{t}\right]}{E\left[X_{t-r}\right]} / \frac{\exp \left(E\left[\ln X_{t}\right]\right)}{\exp \left(E\left[\ln X_{t-r}\right]\right)}=(1+\beta) /\left(\exp \left(\beta^{*}\right)\right.$, where $\beta$ and $\beta^{*}$ stand for the growth rate of the arithmetic and geometric means, respectively, over the full sample period, ( $\mathrm{t}=2015$ and $\mathrm{t}-\mathrm{r}=2006)$. Column (5) is obtained as [column (3)-1]/[column (2)-1]. Similarly for column (6).
} 
Table 3: Differences between the arithmetic and geometric mean (2006-2015)

(Contributions of changes in variance and skewness)

\begin{tabular}{l|c|c|c|c|c}
\hline \hline & $\begin{array}{c}\text { Observed } \\
\text { Difference }\end{array}$ & $\begin{array}{c}\text { changes } \\
\text { in } \\
\text { variance }\end{array}$ & $\begin{array}{c}\text { changes in } \\
\text { variance } \\
\text { and skewness }\end{array}$ & $\begin{array}{c}\text { explained } \\
\text { by } \\
\text { variance }\end{array}$ & $\begin{array}{c}\text { explained } \\
\text { by variance } \\
\text { and skewness }\end{array}$ \\
\hline \hline$(1)$ & $(2)$ & $(3)$ & $(4)$ & $(5)$ & $(6)$ \\
\hline \multicolumn{5}{c}{ Labor Productivity } \\
\hline Agriculture & 0.990 & 1.080 & 1.018 & -7.611 & -1.764 \\
Manufacturing & 1.034 & 1.031 & 1.016 & 0.914 & 0.482 \\
Tradable Serv. & 1.185 & 1.085 & 1.105 & 0.461 & 0.567 \\
Nontradable Serv. & 1.071 & 1.072 & 1.044 & 1.017 & 0.614 \\
Total economy & 1.073 & 1.065 & 1.042 & 0.892 & 0.576 \\
\hline \multicolumn{5}{|c|}{ TFP } \\
\hline Agriculture & 0.949 & 0.960 & 0.958 & 0.790 & 0.829 \\
Manufacturing & 1.102 & 0.990 & 1.053 & -0.095 & 0.523 \\
Tradable Serv. & 1.194 & 1.094 & 1.136 & 0.483 & 0.702 \\
Nontradable Serv. & 1.147 & 1.036 & 1.079 & 0.244 & 0.538 \\
Total economy & 1.246 & 1.028 & 1.092 & 0.115 & 0.373 \\
\hline \hline
\end{tabular}

Note: Numbers in column (2) are the ratio between productivity growth based on the arithmetic and the geometric means over the full sample period. See footnote (14). The second and third columns show the second term on the right-hand-side of equation (2) with just the variance term (column (3)) or with both the variance and the skewness terms (column (4)). Columns (5) and (6) show the ratios of columns (3) and (4) to column (2), respectively.

For labor productivity, the results in Table 3 show that changes in the variance and skewness of the (size-weighted) log-productivity distribution account, on average, for more than 50 percent of the difference in the growth rates of the arithmetic and geometric means. The differences in the two means are, in most cases, the result of an increase in the variance combined with a decline in the skewness of the log labor-productivity distribution. The two results together - increase in the variance and decline in skewness - suggest that the difference between the most and the least (size-weighted) productive firms in Portugal increased, but that the difference was made larger by the least productive firms becoming less productive.

Turning now to TFP, Table 3 shows that changes in the variance and skewness of the log-TFP distribution also account for an important part of the difference in the growth rates of the arithmetic and geometric means. The differences in the two means are now 
the result of an increase both in the variance and the skewness of the (size-weighted) $\log$-TFP distribution. For the non-tradable service sector and the tradable service sector, the importance of changes in the variance and the skewness are about equal. For these sectors, both the variance and skewness increased between 2006 and 2015, and together they explain between 54 percent and 70 percent of the difference between the estimates of average productivity growth based on the arithmetic and geometric means. For manufacturing, most of the difference between the average productivity growth based on the arithmetic and the geometric means is explained by changes in the skewness of firm-level $\log$-TFP.

Correlations involving size and productivity levels, on the one side, and size and productivity changes, on the other, determine how the variance and skewness of the log productivity distributions evolve over time, as firm-size and firm-level productivity change. An interesting result that emerges from Table 3 is that, in general, there seems to have been an increase in the variance of both the $\log$-TFP and $\log$ labor-productivity distributions but, while the skewness of the log TFP distribution increased, the skewness of the log labor-productivity distribution declined. These results suggest that levels and changes of (size-weighted) $\log$-TFP and log labor-productivity at the firm-level are not perfectly correlated, so that it is possible for the moments of the two distributions to evolve in different directions. This can also be inferred from Table 2 (as well as from Tables 4 and 5 below), which shows that productivity growth and productivity decompositions delivered by the geometric mean for the two productivity measures (labor productivity and TFP) differ sometimes considerably from each other.

\subsection{Consequences for productivity decompositions}

We now investigate the extent to which the differences between the arithmetic and the geometric means have large implications for the type of productivity decompositions, dis- 
cussed in subsection 2.2 .

Tables 4 and 5 record the contributions for accumulated productivity growth of surviving, entering and exiting firms, as delivered by the arithmetic and geometric means for the two productivity measures. Numbers for the "within", "between" and the "cross" components are also shown. To make the interpretation easier, the tables also include the differences between the contributions delivered by the two statistics.

As could be expected, given the evidence in the previous subsection, the tables show that conclusions about the relative importance of the contributions of the three types of firms differ, sometimes substantially, depending on whether one looks at the arithmetic or the geometric mean. For instance, the results for aggregate TFP in Table 5 show that the contribution of surviving firms for aggregate productivity growth using the arithmetic mean is positive and very large $(15.0 \mathrm{pp})$, but small and negative $(-0.5 \mathrm{pp})$ when the geometric mean is used. Of course, these different aggregate contributions of surviving firms reflect different contributions of the "within" (23.3 pp of the arithmetic mean against $3.1 \mathrm{pp}$ of the geometric mean), "between" (14.0 pp against $4.7 \mathrm{pp})$ and "cross" effects (-22.3 pp against $-8.3 \mathrm{pp})$.

Large differences in these effects also appear at the sectoral level. For instance, with the exception of agriculture, for all the other cases the "within" effect of the arithmetic mean is larger than that of the geometric mean. There are cases in which the differences are not only quantitatively but also qualitatively different. For tradable services the arithmetic mean suggests that the contribution of the "within" effect over the 2006-2015 period was large and positive (18.8 pp for labor productivity and $32.1 \mathrm{pp}$ for TFP), but the geometric mean suggests a large negative contribution (-16.7 pp and $-9.1 \mathrm{pp}$, respectively). The fact that the "within effect" of the arithmetic mean is higher than that of the geometric mean is in line with the general rule derived in subsection 2.2, according to which one should expected the "within" effect to be larger under the arithmetic mean, except if productivity 
changes are strongly negatively correlated with productivity levels. This condition is met only by agriculture. In our data the first term of the "within" effect in equation (14) is always negative (which implies a negative correlation between productivity changes and size-weighted productivity levels), but with the exception of agriculture, is not big enough to offset the contribution coming from the second term, which, as shown above, is always positive.

Regarding the "between" effect, we see from Tables 4 and 5 that the difference in the contributions of the arithmetic and the geometric mean is always positive, with the exception of labor productivity for agriculture (which is negative, but small). In the case of TFP, the contributions delivered by the arithmetic mean are, on average, more than twice as large the contributions of the geometric mean. According to the discussion in subsection 2.2, these results suggest that (with the exception of agriculture) increases in size were mostly associated with either low or high productivity firms, i.e., firms in the tails of the productivity distribution.

In turn, the difference in the "cross" effects is usually negative and very large, i.e., the contributions of the "cross" effect delivered by the arithmetic mean are much lower than the contributions recorded by the geometric mean (again with the exception of labor productivity in agriculture). In our dataset this negative difference is the result of positive contribution coming from the first term in equation (14), which is more than offset by the negative contribution of the second term. The fact that this second term is negative shows that, in the case of Portugal, larger productivity changes tend to be associated with larger negative size changes. Given that in these type of decompositions there is usually, in empirical terms, an offsetting effect of the "between" and "cross" terms, it might be more interesting to look at the sum of these two contributions ${ }^{17}$ If we take the sum

\footnotetext{
${ }^{17}$ This offsetting effect is consistent with the view that idiosyncratic productivity shocks induce changes in size and that changes in size, in turn, induce productivity changes, given decreasing within-firm returns. The negative cross term is also consistent with the idea that downsizing may be productivity enhancing.
} 
Table 4: Labor productivity decomposition

(accumulated contributions 2006-2015)

\begin{tabular}{|c|c|c|c|c|c|c|c|c|c|}
\hline \multirow[b]{2}{*}{ Sectors } & \multicolumn{4}{|c|}{ Survivors } & \multirow[b]{2}{*}{ Entry } & \multirow[b]{2}{*}{ Exit } & \multirow{2}{*}{$\begin{array}{c}\text { Net } \\
\text { entry }\end{array}$} & \multirow{2}{*}{$\begin{array}{c}\text { Total } \\
\text { reallocation }\end{array}$} & \multirow{2}{*}{$\begin{array}{c}\text { Total } \\
\text { change }\end{array}$} \\
\hline & Within & Between & cross & Total & & & & & \\
\hline$(1)$ & $(2)$ & $(3)$ & $(4)$ & $(5)$ & $(6)$ & $(7)$ & $(8)$ & $(9)$ & $(10)=(5)+(8)$ \\
\hline \multicolumn{10}{|l|}{ Agriculture } \\
\hline Arithmetic & 21.1 & 19.5 & -45.5 & -4.8 & -21.6 & 14.6 & -7.0 & -33.0 & -11.9 \\
\hline Geometric & 33.7 & 21.1 & -55.0 & -0.1 & -31.1 & 18.9 & -12.2 & -46.1 & -12.4 \\
\hline Difference & -12.6 & -1.6 & 9.5 & -4.7 & 9.5 & -4.3 & 5.2 & 13.1 & 0.5 \\
\hline \multicolumn{10}{|l|}{ Manufacturing } \\
\hline Arithmetic & 21.4 & 12.4 & -20.3 & 13.4 & -6.4 & 13.2 & 6.8 & -1.1 & 20.2 \\
\hline Geometric & 12.7 & 10.0 & -12.0 & 10.8 & -12.2 & 17.9 & 5.7 & 3.7 & 16.5 \\
\hline Difference & 8.7 & 2.4 & -8.3 & 2.6 & 5.8 & -4.7 & 1.1 & -4.8 & 3.7 \\
\hline \multicolumn{10}{|l|}{ Tradable services } \\
\hline Arithmetic & 18.8 & 70.5 & -103.7 & -14.4 & 7.3 & -4.5 & 2.8 & -30.4 & -11.7 \\
\hline Geometric & -16.7 & 29.6 & -43.8 & -30.9 & -16.5 & 17.8 & 1.3 & -12.9 & -29.7 \\
\hline Difference & 35.5 & 40.9 & -59.9 & 16.5 & 23.8 & -22.3 & 1.5 & -17.5 & 18.0 \\
\hline \multicolumn{10}{|l|}{ Nontradable services } \\
\hline Arithmetic & 34.1 & 15.8 & -40.5 & 9.3 & -12.3 & 7.0 & -5.3 & -30.0 & 4.0 \\
\hline Geometric & 19.6 & 12.5 & -31.6 & 0.4 & -21.7 & 18.3 & -3.4 & -22.5 & -3.0 \\
\hline Difference & 14.5 & 3.3 & -8.9 & 8.9 & 9.4 & -11.3 & -1.9 & -7.5 & 7.0 \\
\hline \multicolumn{10}{|l|}{ Total economy } \\
\hline Arithmetic & 27.3 & 23.4 & -44.7 & 6.0 & -9.0 & 8.4 & -0.6 & -21.9 & 5.4 \\
\hline Geometric & 12.7 & 14.5 & -28.6 & -1.4 & -19.6 & 19.3 & -0.3 & -14.4 & -1.8 \\
\hline Difference & 14.6 & 8.9 & -16.1 & 7.4 & 10.6 & -10.9 & -0.3 & -7.5 & 7.2 \\
\hline
\end{tabular}

Note: Total economy also includes construction, but excludes electricity, gas and water services. Net entry is the sum of columns (6) and (7). Total reallocation is the sum of columns (3), (4) and (8).

of the "between" and "cross" effect, which can be interpreted as a measure of resource reallocation among surviving firms (sum of columns (3) and (4) in Tables 4 and 5), we conclude that, with the exception of labor productivity for agriculture, the contribution of resource reallocation for productivity growth is lower under the arithmetic mean. According to subsection 2.2, this result stems from a negative covariance between changes in size $\left(\Delta \mu_{i, t}^{s}\right)$ and $\lambda_{i, t}$. Overall, for surviving firms, the arithmetic mean suggests a larger contribution of the "within" effect, but a lower contribution of "resource reallocation", than the geometric mean.

Now, if we look at the contributions of entering and exiting firms, we conclude that they also differ between the two means. For instance, in the case of labor productivity the contribution of entry delivered by the arithmetic mean is always larger than that of the geometric mean but, with the exception of agriculture and nontradable services, 
Table 5: TFP decomposition

(accumulated contributions 2006-2015)

\begin{tabular}{|c|c|c|c|c|c|c|c|c|c|}
\hline \multirow[b]{2}{*}{ Sectors } & \multicolumn{4}{|c|}{ Survivors } & \multirow[b]{2}{*}{ Entry } & \multirow[b]{2}{*}{ Exit } & \multirow{2}{*}{$\begin{array}{l}\text { Net } \\
\text { entry }\end{array}$} & \multirow{2}{*}{$\begin{array}{c}\text { Total } \\
\text { reallocation }\end{array}$} & \multirow{2}{*}{$\begin{array}{c}\text { Total } \\
\text { change }\end{array}$} \\
\hline & Within & Between & cross & Total & & & & & \\
\hline (1) & $(2)$ & $(3)$ & $(4)$ & $(5)$ & $(6)$ & (7) & $(8)$ & (9) & $(10)=(5)+(8)$ \\
\hline \multicolumn{10}{|l|}{ Agriculture } \\
\hline Arithmetic & 4.3 & 17.4 & -19.0 & 2.7 & 5.8 & -4.0 & 1.8 & 0.2 & 4.5 \\
\hline Geometric & 4.7 & 2.5 & -2.4 & 4.8 & 2.9 & 1.8 & 4.7 & 4.8 & 9.5 \\
\hline Difference & -0.4 & 14.9 & -16.6 & -2.1 & 2.9 & -5.8 & -2.9 & -4.6 & -5.0 \\
\hline \multicolumn{10}{|l|}{ Manufacturing } \\
\hline Arithmetic & 24.7 & 10.9 & -19.8 & 15.8 & -7.6 & 8.5 & 0.9 & -8.0 & 16.7 \\
\hline Geometric & 6.7 & 9.4 & -11.4 & 4.7 & 8.9 & -6.6 & 2.3 & 0.3 & 7.1 \\
\hline Difference & 18.0 & 1.5 & -8.4 & 11.1 & -16.5 & 15.1 & -1.4 & -8.3 & 9.6 \\
\hline \multicolumn{10}{|l|}{ Tradable services } \\
\hline Arithmetic & 32.1 & 13.8 & -21.3 & 24.6 & -53.3 & 57.3 & 4.0 & -3.5 & 28.6 \\
\hline Geometric & -9.1 & 2.6 & -3.2 & -9.7 & 14.3 & 4.3 & 18.6 & 18.0 & 8.9 \\
\hline Difference & 41.2 & 11.2 & -18.1 & 34.3 & -67.6 & 53.0 & -14.6 & -21.5 & 19.7 \\
\hline \multicolumn{10}{|l|}{ Nontradable services } \\
\hline Arithmetic & 20.5 & 17.1 & -26.5 & 11.2 & -20.0 & 17.7 & -2.3 & -11.7 & 8.9 \\
\hline Geometric & 7.2 & 6.4 & -10.6 & 3.0 & -26.8 & 18.6 & -8.2 & -12.4 & -5.3 \\
\hline Difference & 13.3 & 10.7 & -15.9 & 8.2 & 6.8 & -0.9 & 5.9 & 0.7 & 14.2 \\
\hline \multicolumn{10}{|l|}{ Total economy } \\
\hline Arithmetic & 23.3 & 14.0 & -22.3 & 15.0 & -33.1 & 36.1 & 3.0 & -5.3 & 18.0 \\
\hline Geometric & 3.1 & 4.7 & -8.3 & -0.5 & -11.4 & 7.6 & -3.8 & -7.4 & -4.3 \\
\hline Difference & 20.2 & 9.3 & -14.0 & 15.5 & -21.7 & 28.5 & 6.8 & 2.1 & 22.3 \\
\hline
\end{tabular}

Note: Total economy also includes construction, but excludes electricity, gas and water services. Net entry is the sum of columns (6) and (7). Total reallocation is the sum of columns (3), (4) and (8).

the opposite holds for TFP (Table 5) 18 Also, for labor productivity the contribution of exiting firms is always lower under the arithmetic mean. In some cases, the two means even suggest contributions with opposite signs regarding entering and exiting. This is the case of tradable services for labor productivity and of manufacturing for TFP. In particular, Figure 4, which records the accumulated contributions over time of entry and exit for TFP growth in manufacturing, shows that the contributions of entry are systematically negative, according to the arithmetic mean, but systematically positive, according to the geometric mean. Taken at face value, these results imply that entering firms are less productive than surviving firms according to the arithmetic mean, but more productive

\footnotetext{
${ }^{18}$ Note that the arithmetic and the geometric means deliver similar aggregate dynamics for labor productivity in agriculture, but the contributions of some of the components, like the "within" effect, the "entry" effect or "total reallocation" are very different. These results show that even similar aggregate productivity growth rates of the two means may hide very different productivity decompositions.
} 


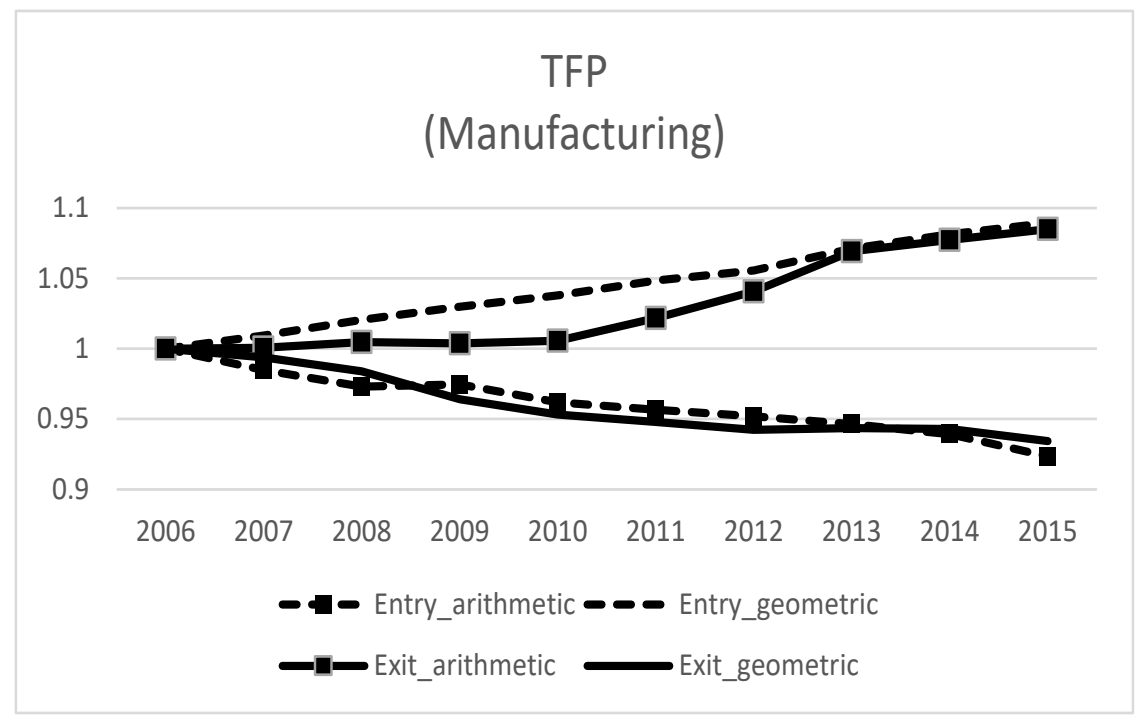

Figure 4: Manufacturing (TFP): Entry and Exit

than surviving firms according to the geometric mean (see equations (11) and (12)). A similar situation occurs with the exiting firms. These firms emerge as less productive than surviving firms according to the arithmetic mean, but more productive than surviving firms, according to the geometric mean.

Finally, we look at the "net entry" contribution in column (8) and "total reallocation" in column (9) of Tables 4 and 5. Even though these aggregate contributions tend to mitigate the differences between the two statistics, some quantitative and qualitative differences are still observable. In the case of TFP, we see that for the total economy the accumulated contribution of "net entry" is positive according to the arithmetic mean (3.0 pp), but negative according to the geometric mean (-3.8 pp). Similarly, for tradable services and manufacturing the contribution of "total reallocation" is negative according to the arithmetic mean, but positive according to the geometric mean.

In summary, the evidence in this section shows that in the case of Portugal the use of the arithmetic or the geometric mean leads to substantially different conclusions regarding aggregate productivity dynamics and productivity growth decompositions, casting serious 
doubts on the conclusions obtained so far in the empirical literature, which have been based almost exclusively on the use of the geometric mean.

\section{Conclusions}

This paper investigates the use of the arithmetic or the geometric means of firm-level productivity to study aggregate productivity dynamics. We establish the conditions under which the two means are expected to yield different outcomes, and show that the commonly used methods to decompose productivity growth, such as those proposed in Baily et al. (1992), Griliches and Regev (1995), Olley and Pakes (1996), Foster et al. (2001) and Melitz and Polanec (2015), can deliver substantially different results regarding productivity decompositions, when using one or the other statistic. These findings cast serious doubts on the conclusions obtained so far in the literature, which has made an extensive use of the geometric mean, and raise the question of which statistic to use in empirical applications.

Based on the evidence documented in this paper, we suggest using the arithmetic mean whenever the analysis is based on labor productivity, measured by either the value added or gross output per worker, with employment shares or hours worked used as weights. The arithmetic mean has an immediate counterpart to the aggregate measure of labor productivity, so that their changes match the changes in labor productivity that can be computed from the National Accounts aggregate data.

In the case of TFP, the choice between the two means is much less obvious as it may depend on the researchers preferences and questions being addressed. Under these circumstances, we suggest that researchers compute both the arithmetic and the geometric mean, as a robustness test, and, if differences are large, use the results in this paper to investigate the sources of such differences. Looking at changes in the moments of the firm-level log-productivity distribution, or at the correlations between productivity levels, 
size and productivity changes involving surviving, entering and exiting firms, will allow identifying the possible sources of the differences between the two statistics. These might well be related to economically important situations, such as the presence of catching-up processes (small and low productivity firms displaying higher productivity growth) or of large and high productivity "superstar" firms.

\section{References}

Amador, J. and Soares, A. C. (2012), Competition in the Portuguese economy: An overview of classical indicators, Working Paper 8, Banco de Portugal.

Baily, M., Hulten, C. and Campbell, D. (1992), 'Productivity dynamics in manufacturing plants', Brookings Papers on Economic Activity: Microeconomics 4, 187-267.

Bartelsman, E. and Dhrymes, P. J. (1998), 'Productivity dynamics: U.S. manufacturing plants, 1972-1986', Journal of Productivity Analysis 9, 5-34.

Decker, R. A., Haltiwanger, J., Jarmin, R. S. and Miranda, J. (2017), 'Declining dynamism, allocative efficieny and the productivity slowdown', American Economic Review 107(5), 322-326.

Decker, R. A., Haltiwanger, J., Jarmin, R. S. and Miranda, J. (2018), Changing business dynamism and productivity: Shocks vs. responsiveness, Working paper No. 24236, NBER.

Dias, D. A. and Marques, C. R. (2019), Every cloud has a silver lining: Cleansing effects of the Portuguese financial crisis, International Finance Discussion Papers 1250, Board of Governors of the Federal Reserve System. 
Dias, D. A., Marques, C. R. and Richmond, C. (2019), 'A tale of two sectors: Why is misallocation higher in services than in manufacturing?', The Review of Income and Wealth (forthcoming).

Foster, L., Grim, C. and Haltiwanger, J. (2016), 'Reallocation in the great recession: Cleansing or not?', Journal of Labor Economics 34(S1), S293-S331.

Foster, L., Haltiwanger, J. and Krizan, C. J. (2001), Aggregate productivity growth: Lessons from microeconomic evidence, in 'New Developments in Productivity Analysis', ed. Carles R. Hulten, Edward R. Dean, and Michael J. Harper, Chicago and London: University of Chicago Press, chapter 8, pp. 303-372.

Foster, L., Haltiwanger, J. and Krizan, J. C. (2006), 'Market selection, reallocation, and restructuring in the u.s. retail trade sector in the 1990s', Review of Economics and Statistics 88(4), 748-758.

Griffin, N. N. and Odaki, K. (2009), 'Reallocation and productivity growth in Japan: Revisiting the lost decade of the 1990s', Journal of Productivity Analysis 31(2), 125136.

Griliches, Z. and Regev, H. (1995), 'Firm productivity in Israeli industry 1979-1988', Journal of Econometrics 65(1), 175 - 203.

Hallward-Driemeier, M. and Rijkers, B. (2013), 'Do crises catalyze creative destruction? Firm-level evidence from Indonesia', The Review of Economics and Statistics 95(5), 1788-1810.

Harry, G. H., Littlewood, J. E. and Pólya, G. (1952), Inequalities, Cambridge University Press. 
Levinsohn, J. and Petrin, A. (2003), 'Estimating production functions using inputs to control for unobservables', The Review of Economic Studies 70(2), 317-341.

Liu, L. and Tybout, J. R. (1996), Productivity growth in Chile and Colombia: The role of entry, exit, and learning, in 'Industrial Evolution in Developing Countries', Mark J. Roberts and James R. Tybout edn, Oxford University Press, chapter 4, pp. 73-103.

Marshall, A. W., Olkin, I. and Arnold, B. C. (2010), Inequalities: Theory of Majorization and its Applications, Springer.

Melitz, M. J. and Polanec, S. (2015), 'Dynamic Olley-Pakes productivity decomposition with entry and exit', The RAND Journal of Economics 46(2), 362-375.

Olley, G. S. and Pakes, A. (1996), 'The dynamics of productivity in the telecommunications equipment industry', Econometrica 64(6), 1263-1297.

Santos Silva, J. M. C. and Tenreyro, S. (2006), 'The log of gravity', The Review of Economics and statistics 88(4), 641-658.

\section{Appendix A: The econometrics of the arithmetic and the geometric means}

In this Appendix we show that the differences in average productivity growth implied by the differences in average productivity based on the arithmetic and the geometric means can be seen as a special case of the problems of using log-linearized models in econometrics.

Let us assume that we have information on firm-level productivities for $\mathrm{T}+1$ time periods $(\mathrm{t}=0,1,2, \ldots \mathrm{T})$. As shown by Santos Silva and Tenreyro (2006), the arithmetic averages for each time period can be calculated by estimating by pseudo-Poisson maximum 
likelihood (PPML) the equation:

$$
P_{i t}=\exp \left(\alpha+\sum_{j=1}^{T} \gamma_{j} * I_{j}\right) \epsilon_{i t}
$$

and the geometric averages can be calculated by estimating by OLS the following equation

$$
\ln \left(P_{i t}\right)=\alpha+\sum_{j=1}^{T} \gamma_{j} * I_{j}+\ln \left(\epsilon_{i t}\right)
$$

where $I_{j}$ is an indicator variable that takes the value 1 if $t=j$ and 0 otherwise $(\mathrm{j}=1,2, . . \mathrm{T})$.

From these equations, the cumulative change in average aggregate productivity between periods t and 0 based on the arithmetic mean is given by $\exp \left(\hat{\gamma}_{t}^{P P M L}\right)$, while the cumulative change in average aggregate productivity between periods $\mathrm{t}$ and 0 based on the geometric mean is given by $\exp \left(\hat{\gamma}_{t}{ }^{O L S}\right)$.

Importantly, as shown in Santos Silva and Tenreyro (2006), if the error term $\epsilon_{i t}$ is not i.i.d., the estimates of $\alpha$ and $\gamma_{j}$ based on OLS and PPML will be different, and those based on OLS will be biased while those based on PPML will not. Because the assumption of i.i.d. error terms will be violated if $2^{\text {nd }}$ - or higher-order moments - of the distribution of log-productivity are not constant over time, it is very likely that the analysis of productivity dynamics based on the arithmetic and the geometric means of productivity will lead to different conclusions. 